\title{
Reliability of the Dexcom G6 Continuous Glucose Monitor During Hyperbaric Oxygen Exposure
}

\author{
Enoch Huang, MD, Shaban Demirel, $\mathrm{PhD}_{1}^{2}$ Chanelle Bliss, $\mathrm{CHT}$, \\ Davut Savaser, MD, and Jessica R. Castle, MD $^{3}$
}

\begin{abstract}
Background: People with diabetes-related ulcers may benefit from hyperbaric oxygen $\left(\mathrm{HBO}_{2}\right)$ therapy and from continuous glucose monitors (CGM). Although blood glucose (BG) meters based on glucose oxidase (GO) report erroneously low values at high $\mathrm{pO}_{2}$, $\mathrm{BG}$ meters based on glucose dehydrogenase (GD) do not. We therefore examined the performance of a GO-based CGM system in comparison to GO-based and GD-based BG systems in normobaric air (NBAir), hyperbaric air (HBAir), and $\mathrm{HBO}_{2}$ environments.

Materials and Methods: Twenty-six volunteers without diabetes mellitus (DM) wore Dexcom G6 CGM systems and provided periodic blood samples before, during, and after a standard $\mathrm{HBO}_{2}$ treatment consisting of three 30min intervals of $\mathrm{HBO}_{2}$ separated by two 5-min intervals of HBAir. Accuracy of the CGM and GO-based BG meter were assessed by comparisons with the GD-based values.

Results: The mean absolute relative difference for the CGM system was $15.96 \%$ and for the GO-based meter was $8.52 \%$. Compared to NBAir, $\mathrm{HBO}_{2}$ exposure resulted in significantly higher CGM values $(+3.76 \mathrm{mg} / \mathrm{dL}$, $P<0.001)$ and significantly lower GO-based meter values $(-10.38 \mathrm{mg} / \mathrm{dL}, P<0.001)$. Pre- $\mathrm{HBO}_{2}$ and post- $\mathrm{HBO}_{2}$ values obtained in NBAir were also significantly different when measured by CGM $(+4.13 \mathrm{mg} / \mathrm{dL}, P=0.015)$ or the GO-based meter $(-9.04 \mathrm{mg} / \mathrm{dL}, P<0.001)$.

Conclusions: In volunteers without $\mathrm{DM}, \mathrm{HBO}_{2}$ exposure results in statistically significant differences in glucose measurements obtained with GO-based devices, but not a GD-based device. Standard $\mathrm{HBO}_{2}$ treatment results in statistically significant effects on glucose concentrations. These differences are of unlikely clinical significance.
\end{abstract}

Keywords: Hyperbaric oxygen therapy, $\mathrm{HBO}_{2}$, Continuous glucose monitors (CGM), Hypoglycemia.

\section{Introduction}

D IABETES MELlitus (DM) Is an epidemic of global proportion with a steadily rising prevalence. It is believed that at least $15 \%$ of people living with DM will develop a lower extremity foot ulcer during their lifetime. ${ }^{1,2}$ The annual incidence of foot ulcer development, which often requires hyperbaric oxygen $\left(\mathrm{HBO}_{2}\right)$ therapy, ${ }^{3}$ is $5 \%-6 \%$ among people living with DM. ${ }^{1,2,4}$ However, $\mathrm{HBO}_{2}$ is thought to lower estimated glucose values (EGVs) over the course of a treatment, ${ }^{5-15}$ leading to treatment protocols that rely on pre- $\mathrm{HBO}_{2}$ EGV to determine whether patients can be safely treated that same day or not. ${ }^{16}$ This usually involves multiple finger sticks performed with point-of-care (POC) glucometers. For multiplace hyperbaric facilities, patients may have their blood glucose (BG) tested during therapy; however, this is not a possibility for patients in monoplace hyperbaric facilities.

Continuous glucose monitors (CGM) allow monitoring of EGV without the need for multiple finger sticks. ${ }^{17,18}$ Patients have a sensor inserted transcutaneously with a sensor wire that is located in the interstitial subcutaneous space. This sensor wire uses a glucose oxidase (GO) chemical reaction to generate an electrical signal that is converted into an EGV. A transmitter is attached to the sensor that records the EGV

\footnotetext{
${ }^{1}$ Legacy Emanuel Medical Center; ${ }^{2}$ Legacy Research Institute; ${ }^{3}$ Oregon Health and Science University, Harold Schnitzer Diabetes Health Center, Portland, Oregon.

This work was presented at the Undersea and Hyperbaric Medical Society Annual Scientific Meeting in San Juan, Puerto Rico in June 2019. The proceedings of the meeting and abstract were published in Undersea and Hyperbaric Medicine 2019, 46(4), 561.

(c) Enoch Huang, et al., 2020; Published by Mary Ann Liebert, Inc. This Open Access article is distributed under the terms of the Creative Commons License (http://creativecommons.org/licenses/by/4.0), which permits unrestricted use, distribution, and reproduction in any medium, provided the original work is properly credited.
} 
and transmits the data to a receiver or smartphone. The transmitter has a 3-h storage capacity in case there is a temporary disconnection with the receiver. Missing data can be backfilled when the data connection is restored. CGM offers a unique opportunity to monitor EGV before, during, and after $\mathrm{HBO}_{2}$, but CGM reliability in a $\mathrm{HBO}_{2}$ environment has not been established. To date, there have been only two publications one in vitro and one in vivo - reporting the effects of hypobaric and hyperbaric chamber exposures on a CGM, however, those studies were done with air and not oxygen. ${ }^{19,20}$

A patient receiving $\mathrm{HBO}_{2}$ may have alveolar $\mathrm{pO}_{2}$ over $1800 \mathrm{mmHg}$ with tissue $\mathrm{pO}_{2}$ over $1000 \mathrm{mmHg}$. POC glucometers utilizing GO test strips have been shown to underestimate glucose levels when exposed to high $\mathrm{pO}_{2}$ levels, ${ }^{21-24}$ while those using glucose dehydrogenase (GD) test strips are not affected by high $\mathrm{pO}_{2}$ levels. ${ }^{24}$ Hyperbaric protocols often provide high glycemic index carbohydrates to patients who do not have a minimum pretreatment glucose level. ${ }^{16}$ Underestimation of blood glucose levels (BGLs) may result in unnecessary carbohydrate supplements and iatrogenic hyperglycemia. Before EGVs produced by CGMs that utilize a GO reaction are used in clinical decision making it is imperative that their accuracy be established.

\section{Materials and Methods}

A commercial Dexcom G6 CGM (Dexcom, Inc., San Diego, CA) was placed on individuals without DM who were given a standard $\mathrm{HBO}_{2}$ treatment at 2.4 atmospheres absolute (ATA) in a multiplace chamber (OxyHeal Systems, San Diego, CA) using three 30-min oxygen breathing periods separated by two 5-min air breaks. We compared the CGM results against the hospital's Nova StatStrip POC glucometer (Nova Biomedical, Waltham, MA), which uses an ion selective electrode GO reaction, and a Contour Next POC glucometer that uses a flavin adenine dinucleotide (FAD) GD reaction (Ascensia Diabetes Care, Parsipanny, NJ). We obtained concurrent transcutaneous oximetry measurements (TCOM) no farther than $3 \mathrm{~cm}$ from the insertion site of the CGM to confirm elevated tissue $\mathrm{pO}_{2}$. We calculated differences in EGV between the three different pressure+inhaled gas conditions (normobaric air [NBAir], hyperbaric air [HBAir], and $\mathrm{HBO}_{2}$ ). Linear mixed effects regression models were used to perform the statistical analyses as they can account for repeated measurements made from each participant. Our fitted models allowed for individuals to have different overall levels of estimated glucose.

\section{Mean absolute relative difference}

As GD glucometers are not affected by $\mathrm{pO}_{2},{ }^{24}$ we used the Contour glucometer as a reference standard. We calculated the mean absolute relative difference (MARD) of the Dexcom and Novastat glucometer readings against the Contour at each of the time points.

\section{Blood sampling}

We obtained deep fingerstick capillary blood samples for testing using a 28-gauge lancet. When in the hyperbaric chamber, blood samples were drawn up using a micro-pipette in preparation for transfer through a medication transfer lock. Testing of the blood samples was performed immediately upon removal from the medication lock, a process that took less than 2 min from the time the blood was collected.

\section{Measurements}

$B G$ readings. All participants agreed to refrain from any oral intake of food or liquids other than water for $2 \mathrm{~h}$ before the study period. This was done to ensure that any fluctuations in BG were unrelated to carbohydrate consumption.

CGM data were recorded at 5-min intervals and wirelessly transmitted to a Dexcom receiver. CGM and POC glucometer readings were recorded at multiple time points (Fig. 1) representing either NBAir $\left(\mathrm{pO}_{2}\right.$ of $\left.159.6 \mathrm{mmHg}\right), \mathrm{HBAir}\left(\mathrm{pO}_{2}\right.$ of $380 \mathrm{mmHg}$ ) and $\mathrm{HBO}_{2}\left(\mathrm{pO}_{2}\right.$ of $\left.1824 \mathrm{mmHg}\right)$. The schedule for blood sampling was as follows:

(1) $30 \mathrm{~min}$ Pre- $\mathrm{HBO}_{2}$ at 1 ATA (NBAir)

(2) $15 \mathrm{~min}$ Pre- $\mathrm{HBO}_{2}$ at 1 ATA (NBAir)

(3) Immediately Pre- $\mathrm{HBO}_{2}$ at 1 ATA (NBAir)

(4) Reaching 2.4 ATA on air (HBAir)

(5) Mid- $\mathrm{O}_{2}$ period 1 at 2.4 ATA $\left(15\right.$ min of $\left.\mathrm{O}_{2}\right)\left(\mathrm{HBO}_{2}\right)$

(6) Post- $\mathrm{O}_{2}$ period 1 at 2.4 ATA $\left(30\right.$ min of $\left.\mathrm{O}_{2}\right)\left(\mathrm{HBO}_{2}\right)$

(7) $\mathrm{Pre}-\mathrm{O}_{2}$ period 2 at 2.4 ATA (HBAir)

(8) $\mathrm{Mid}-\mathrm{O}_{2}$ period 2 at 2.4 ATA $\left(45 \mathrm{~min}\right.$ of $\left.\mathrm{O}_{2}\right)\left(\mathrm{HBO}_{2}\right)$

(9) $\mathrm{Post}_{-} \mathrm{O}_{2}$ period 2 at 2.4 ATA $\left(60 \mathrm{~min}\right.$ of $\left.\mathrm{O}_{2}\right)\left(\mathrm{HBO}_{2}\right)$

(10) Pre- $\mathrm{O}_{2}$ period 3 at 2.4 ATA (HBAir)

(11) $\mathrm{Mid}-\mathrm{O}_{2}$ period 3 at 2.4 ATA $\left(75 \mathrm{~min}\right.$ of $\left.\mathrm{O}_{2}\right)\left(\mathrm{HBO}_{2}\right)$

(12) Post- $\mathrm{O}_{2}$ period 3 at 2.4 ATA $\left(90 \mathrm{~min}\right.$ of $\left.\mathrm{O}_{2}\right)\left(\mathrm{HBO}_{2}\right)$

(13) Immediately Post- $\mathrm{HBO}_{2}$ at 1 ATA (NBAir)

(14) 15 min Post- $\mathrm{HBO}_{2}$ at 1 ATA (NBAir)

(15) $30 \mathrm{~min}$ Post- $\mathrm{HBO}_{2}$ at 1 ATA (NBAir)

\section{Transcutaneous tissue oximetry}

We obtained concurrent TCOM using a Clarke electrode (Radiometer America, Brea, CA) attached no farther than $3 \mathrm{~cm}$ from the Dexcom CGM to measure tissue oxygenation in the region of the CGM. The TCOM value closest to the time of each blood draw was used for analysis.

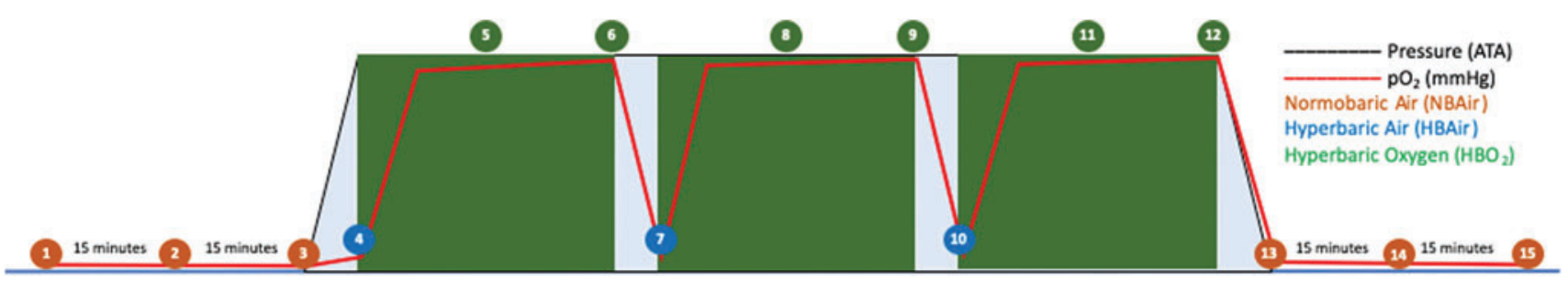

FIG. 1. Glucose testing protocol. Fingerstick blood glucose sampling was performed at each of the time points during a

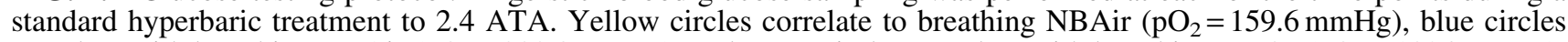
correlate with breathing HBAir $\left(\mathrm{pO}_{2}=383.0 \mathrm{mmHg}\right)$, and green circles correlate with breathing $\mathrm{HBO}_{2}\left(\mathrm{pO}_{2}=1824 \mathrm{mmHg}\right)$. ATA, atmospheres absolute; HBAir, hyperbaric air; NBAir, normobaric air. Color images are available online. 


\section{Participant recruitment}

To minimize fluctuations in $\mathrm{BG}$ as a result of underlying DM, we recruited individuals without DM who were willing to undergo a single hyperbaric exposure to 2.4 ATA while breathing $100 \%$ oxygen. Participants provided their consent to be included in the study after being informed of the study procedures and the risks of participation. Upon enrollment, participants had the Dexcom G6 CGM electrode inserted into the skin of their abdomen. They were scheduled to return $>48 \mathrm{~h}$ after CGM insertion for their hyperbaric exposure. We planned for the recruitment of at least 24 participants.

The inclusion criteria required participants to be willing to participate in all study-related activities. The exclusion criteria included self-reported diagnosis of DM or borderline $\mathrm{DM}$, contraindications to $\mathrm{HBO}_{2}$, or contraindications to having a CGM electrode inserted.

\section{Results}

We enrolled 26 participants but excluded 3 from analysis due to missing or anomalous data. One participant withdrew without undergoing $\mathrm{HBO}_{2}$ exposure, one had missing CGM data during the $\mathrm{HBO}_{2}$ window, and one had anomalous TCOM data during the period of $\mathrm{HBO}_{2}$ caused by a loose TCOM electrode. Mean TCOM values were significantly different between NBAir, $\mathrm{HBAir}$, and $\mathrm{HBO}_{2}$ (Fig. 2).

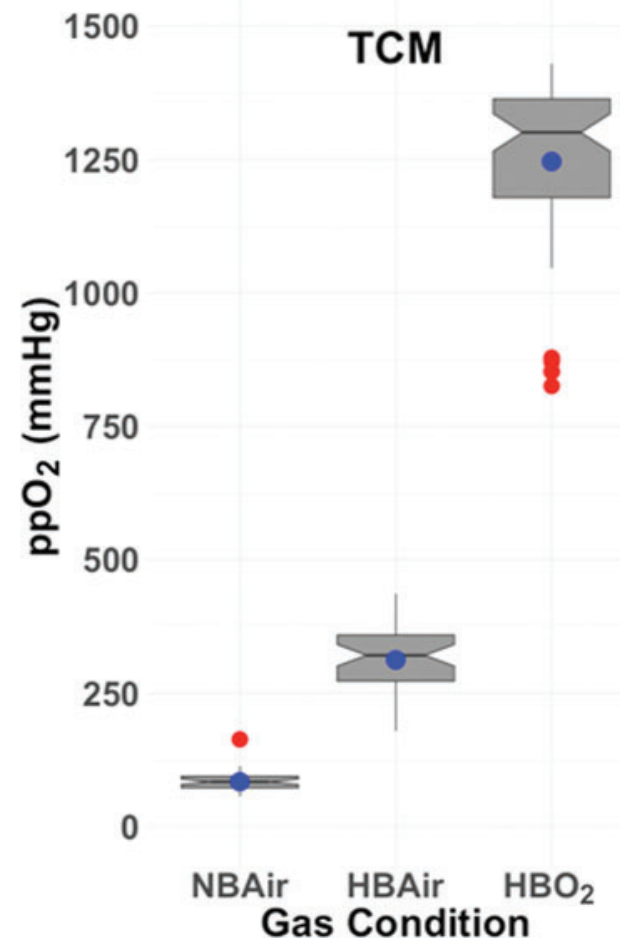

FIG. 2. Box plots of TCOM for each gas+pressure condition. There was a significant change in TCOM between NBAir, HBAir, and $\mathrm{HBO}_{2}$. The notch displays the $95 \%$ confidence interval around the median value, the blue dot shows the mean value, the box covers the IQR (25th percentile to 75th percentile), the whiskers add 1.5 times the IQR to the 75 percentile and subtract 1.5 times the IQR from the 25 percentile, and the red dots show outliers. IQR, interquartile range; TCOM, transcutaneous oximetry measurements. Color images are available online.
Table 1. Characteristics of Study Participants

\begin{tabular}{lc}
\hline Number of participants & $26(3$ excluded) \\
\hline Male & $9(39.1 \%)$ \\
Female & $14(60.9 \%)$ \\
Mean age (years) & 40 \\
Median age (years) & 37 \\
Range (years) & $24-68$ \\
\hline
\end{tabular}

Characteristics of the 23 participants whose data were analyzed are summarized in Table 1 .

EGVs for the Dexcom CGM, the Novastat, and the Contour glucometers are listed in Table 2 and displayed in Figure 3..$^{25,26}$ When comparing HBAir versus NBAir, the Dexcom showed a rise of $2.64 \mathrm{mg} / \mathrm{dL}(2.61 \%, P=0.002)$, the Novastat showed a drop of $2.51 \mathrm{mg} / \mathrm{dL}(2.79 \%, P=0.141)$, and the Contour had a drop of $0.45 \mathrm{mg} / \mathrm{dL}(0.49 \%, P=0.841)$. When comparing $\mathrm{HBO}_{2}$ versus HBAir, the Dexcom showed a rise of $1.12 \mathrm{mg} / \mathrm{dL}(1.08 \%$, $P=0.320)$, the Novastat showed a drop of $7.86 \mathrm{mg} / \mathrm{dL}(8.96 \%$, $P<0.001)$, and the Contour had a drop of $0.72 \mathrm{mg} / \mathrm{dL}(0.79 \%$, $P=0.644)$. When comparing $\mathrm{HBO}_{2}$ versus NBAir, the Dexcom showed a rise of $3.72 \mathrm{mg} / \mathrm{dL}(3.72 \%, P<0.001)$, the Novastat showed a drop of $10.38 \mathrm{mg} / \mathrm{dL}(11.50 \%, P<0.001)$, and the Contour had a drop of $1.17 \mathrm{mg} / \mathrm{dL}(1.28 \%, P=0.177)$.

EGVs for the Dexcom CGM, Novastat, and Contour glucometers immediately before and after $\mathrm{HBO}_{2}$ are listed in Table 3. The Dexcom CGM showed a rise of $4.13 \mathrm{mg} / \mathrm{dL}$ $(4.13 \%, P=0.015)$, the Novastat showed a drop of $9.04 \mathrm{mg} / \mathrm{dL}$ (9.84\%, $P<0.001)$, and the Contour showed a drop of $5.00 \mathrm{mg} / \mathrm{dL}(5.43 \%, P=0.039)$.

When using the Contour as a reference, the cohort average MARD for the Dexcom was $15.96 \%$ (standard deviation (SD) $10.96 \%$, Range $4.50 \%$ to $45.50 \%$ ), whereas the cohort average MARD for the Novastat was $8.52 \%$ (SD $2.39 \%$, Range $4.19 \%$ to $13.27 \%$ ).

\section{Discussion}

The effects of $\mathrm{HBO}_{2}$ on EGV in patients with DM has been described in multiple publications. Springer first reported a mean drop of $51 \mathrm{mg} / \mathrm{dL}$ in 25 patients with DM after $\mathrm{HBO}_{2} \cdot{ }^{13}$ Capelli-Schellpfeffer et al. reported a decrease of $21 \mathrm{mg} / \mathrm{dL}$ in seven patients with DM. ${ }^{12}$ Al-Waili et al. reported that $\mathrm{HBO}_{2}$ lowered EGV by $23 \%$ in a series of 41 patients with $\mathrm{DM}$ and hypertension undergoing $\mathrm{HBO}_{2} \cdot{ }^{6}$ Ekanayake and Doolette reported that five patients with DM experienced an average drop of $3.5 \pm 0.7 \mathrm{mmol} / \mathrm{L}(63 \mathrm{mg} / \mathrm{dL})$ after $\mathrm{HBO}_{2}{ }^{27}$ The first group to conclude that there was no significant change in $\mathrm{BG}$ after $\mathrm{HBO}_{2}$ was Rose et al., who found a maximum decrease of $17 \mathrm{mg} / \mathrm{dL}$ after the first $\mathrm{HBO}_{2}$ treatment and a rise of $5 \mathrm{mg} / \mathrm{dL}$ after $\mathrm{HBO}_{2}$ after the 10th treatment. They did report that the mean pre- $\mathrm{HBO}_{2}$ fasting glucose decreased from 219 to $187 \mathrm{mg} / \mathrm{dL}$ (a drop of $32 \mathrm{mg} / \mathrm{dL}$ ) between the first $\mathrm{HBO}_{2}$ treatment and the tenth $\mathrm{HBO}_{2}$ treatment. ${ }^{14}$ Niezgoda et al. reported an average decline of $62.7 \mathrm{mg} / \mathrm{dL}$ in $272 \mathrm{HBO}_{2}$ treatments. ${ }^{9}$ Trytko reported that patients with DM experienced a mean reduction of BGL of $\sim 2 \mathrm{mmol} / \mathrm{L}(36 \mathrm{mg} / \mathrm{dL})$ with a single $\mathrm{HBO}_{2}$ treatment. ${ }^{7}$ A reduction in BGL was seen in $84 \%$ of treatments involving patients with insulin-dependent DM and $77 \%$ of treatments involving patients with noninsulindependent DM. Fife et al. reported a decrease of between 39 and $47 \mathrm{mg} / \mathrm{dL}$ after $\mathrm{HBO}_{2},{ }^{10}$ and Perdrizet et al. reported a 
Table 2. Estimated Glucose Values for Each Glucometer at Each Pressure/Gas Combination From a Linear Mixed EfFects Regression Model

\begin{tabular}{|c|c|c|c|c|c|c|c|c|c|c|c|c|}
\hline & $\begin{array}{c}\text { NBAir } \\
(\mathrm{mg} / \mathrm{dL})\end{array}$ & $\begin{array}{c}\text { HBAir } \\
(\mathrm{mg} / \mathrm{dL})\end{array}$ & $\begin{array}{c}\mathrm{HBO}_{2} \\
(\mathrm{mg} / \mathrm{dL})\end{array}$ & $\begin{array}{l}\text { HBAir - } \\
\text { NBAir } \\
(m g / d L)\end{array}$ & $\begin{array}{c}\% \\
\text { Change }\end{array}$ & $\mathrm{P}$ & $\begin{array}{c}H B O_{2-} \\
H B A i r \\
(m g / d L)\end{array}$ & $\begin{array}{c}\% \\
\text { Change }\end{array}$ & $\mathrm{P}$ & $\begin{array}{c}\mathrm{HBO}_{2^{-}} \\
\mathrm{NBAir} \\
(\mathrm{mg} / \mathrm{dL})\end{array}$ & $\begin{array}{c}\% \\
\text { Change }\end{array}$ & $\mathrm{P}$ \\
\hline Dexcom & 101.03 & 103.70 & 104.79 & 2.64 & $2.61 \%$ & 0.002 & 1.12 & $1.08 \%$ & 0.320 & 3.72 & $3.72 \%$ & $<0.001$ \\
\hline Novastat & 90.27 & 87.75 & 79.89 & -2.51 & $-2.79 \%$ & 0.141 & -7.86 & $-8.96 \%$ & $<0.001$ & -10.38 & $-11.50 \%$ & $<0.001$ \\
\hline Contour & 91.01 & 90.57 & 89.85 & -0.45 & $-0.49 \%$ & 0.841 & -0.72 & $-0.79 \%$ & 0.644 & -1.17 & $-1.28 \%$ & 0.177 \\
\hline
\end{tabular}

$\mathrm{HBO}_{2}$, hyperbaric oxygen; HBAir, hyperbaric air; NBAir, normobaric air.

decrease of between 17 and $37 \mathrm{mg} / \mathrm{dL} .{ }^{11}$ Wilkinson showed a statistically significant decrease in glucose after receiving $\mathrm{HBO}_{2}$, but did not report a numerical value. ${ }^{15}$ Most recently, Heyboer et al. found a median decrease of $25 \mathrm{mg} / \mathrm{dL}$ in $75.4 \%$ of patients with $\mathrm{DM}$ after receiving $\mathrm{HBO}_{2}$, but concluded that $\mathrm{HBO}_{2}$ did not cause a significant drop in $\mathrm{BG}$ in patients with $\mathrm{DM}^{\overline{8}}$

Of significance, only three of these studies specified the methodology of their glucose testing. Ekanayake et al. tested venous blood using a hexokinase reaction that is unaffected by ambient oxygen, ${ }^{27,28}$ Rose et al. used a GO-based glucometer that had previously been validated against a Yellow Springs Instruments laboratory glucometer, showing that it was unaffected by high environmental oxygen levels. ${ }^{21,29}$ It is interesting to note that Rose et al. demonstrated the smallest variation in pre- versus post- $\mathrm{HBO}_{2}$ glucose measurements including a rise in mean $\mathrm{BG}$ after the 10th treatment. ${ }^{14}$ Heyboer disclosed to this author (E.H.) that their study glucometer used a GD reaction (personal communication).

The effect of $\mathrm{HBO}_{2}$ on the BG of patients without DM has been reported by only a few investigators. Capelli-Schellpfeffer et al. recorded a drop of only $0.57 \mathrm{mg} / \mathrm{dL}$ in 11 patients. Ekanayake and Doolette stated that there was no change in BG, but did not report actual values. ${ }^{27}$ Wilkinson et al. reported no change in glucose in obese men without DM, but did not report a numerical value. ${ }^{15}$ Interestingly, this group utilized a hyperinsulinemic euglycemic clamp to study overweight and obese men both with and without DM who were exposed to a series of $\mathrm{HBO}_{2}$ treatments, demonstrating an increase in insulin sensitivity in the entire cohort of patients. ${ }^{15}$ In an earlier study of nonobese men without DM who received a course of 30 $\mathrm{HBO}_{2}$ sessions, they reported a statistically significant decrease (no numerical value provided) in Hbalc. ${ }^{30}$

Our CGM results revealed a statistically significant increase in EGV when transitioning from NBAir to HBAir and from NBAir to $\mathrm{HBO}_{2}$; however, the change in EGV that we observed $(+3.72 \mathrm{mg} / \mathrm{dL}, P<0.001)$ would generally not be considered clinically relevant (Fig. 3). The Novastat POC glucometer showed a $10.38 \mathrm{mg} / \mathrm{dL}(11.5 \%, P<0.001)$ reduction in EGV when transitioning from NBAir to $\mathrm{HBO}_{2}$, which may be clinically relevant if patients are on a $\mathrm{HBO}_{2}$
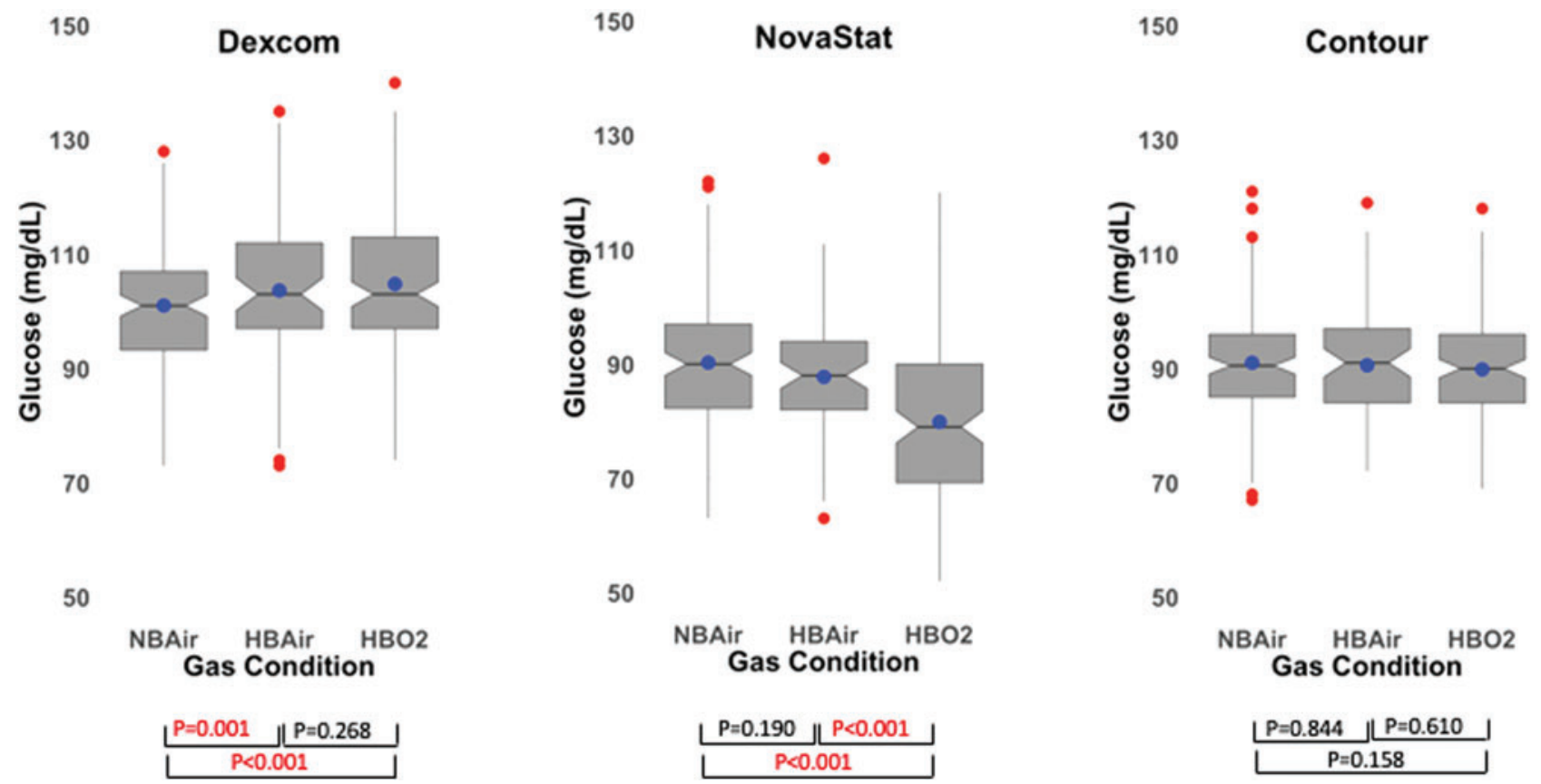

FIG. 3. Box plots of EGV for each gas+pressure condition by glucometer. There was a significant change between NBAir and $\mathrm{HBO}_{2}$ for the Dexcom and NovaStat, but not the Contour. The notch displays the $95 \%$ confidence interval around the median value, the blue dot shows the mean value, the box covers the IQR (25th percentile to 75th percentile), the whiskers add 1.5 times the IQR to the 75 percentile and subtract 1.5 times the IQR from the 25 percentile, and the red dots show outliers. EGV, estimated glucose value. Color images are available online. 
Table 3. Estimated Glucose Values for Each GLUCOMETER IMMEDIATELY BEFORE AND IMMEDIATELY AfTER $\mathrm{HBO}_{2}$ FrOM a LineAr MiXed EFFECTS REGRESSION MODEL

\begin{tabular}{lccccc}
\hline \multicolumn{7}{c}{$\begin{array}{c}\text { Before } \\
\mathrm{HBO}_{2}\end{array}$} & $\begin{array}{c}\text { After } \\
\mathrm{HBO}_{2}\end{array}$ & & & \\
Glucometer & $(\mathrm{mg} / \mathrm{dL})$ & $(\mathrm{mg} / \mathrm{dL})$ & Difference & $\%$ & \multicolumn{1}{c}{$\mathrm{P}$} \\
\hline Dexcom & 99.91 & 104.04 & 4.13 & 4.13 & 0.015 \\
$\quad$ CGM & & & & & \\
Novastat & 91.87 & 82.83 & -9.04 & -9.84 & $<0.001$ \\
Contour & 92.09 & 87.09 & -5.00 & -5.43 & 0.039 \\
\hline
\end{tabular}

CGM, continuous glucose monitoring.

protocol that requires administration of additional carbohydrates before or during treatment. These results confirmed our suspicion that the hospital's GO-based glucometer underestimated glucose values under hyperoxic conditions. This raises concerns about inappropriate carbohydrate supplements being given to patients with $\mathrm{DM}$ while they undergo $\mathrm{HBO}_{2}$, potentially leading to unnecessary episodes of iatrogenic hyperglycemia. As expected, the Contour glucometer showed practically no effect of pressure or gas combination on EGV $(-1.17 \mathrm{mg} / \mathrm{dL},-1.28 \%, P=0.177)$. The insensitivity of this device to changes in atmospheric or tissue oxygen levels is related to its use of FAD GD, rather than GO, as the catalyst. EGVs from the CGM devices were consistently higher than EGVs from either POC glucometer (Fig. 4), which was unexpected given the low bias of Dexcom G6 values with respect to reference values from venous blood as reported in the labeling of the device. ${ }^{31}$ The higher MARD for the Dexcom reflects the positive bias in EGV readings using the CGM.

The previous in vivo report of hypobaric and hyperbaric exposures on CGM function was on a single research par- ticipant without DM who had 48 Medtronic Enlite ${ }^{\mathrm{TM}}$ sensors (Medtronic, Inc., Northridge, CA) implanted on his abdomen and back over two successive days while breathing air. The first 24 sensors were tested in a hypobaric environment $(0.5$ ATA, $\mathrm{pO}_{2}$ of $79.8 \mathrm{mmHg}$ ) on day 1 , while the last 24 sensors were tested in a hyperbaric environment (4 ATA, $\mathrm{pO}_{2}$ of $638.4 \mathrm{mmHg}$ ) on day 2. The Enlite ${ }^{\mathrm{TM}}$ CGM had less accuracy during hypobaric exposures than hyperbaric exposures, and this was theorized to be secondary to microbubbles that developed during sensor insertion. Any bubbles would increase in volume with a decrease in ambient pressure, decreasing the amount of contact - and therefore decreasing accuracybetween the sensor wire and the surrounding interstitial fluid. Conversely, any microbubbles that formed during insertion would have decreased during pressurization to 4 ATA, reducing any issues that may have been present and increasing accuracy. ${ }^{19}$ Similarly, pressurization to 2.4 ATA in our study would have reduced any microbubble volume, and breathing $100 \% \mathrm{O}_{2}$ would have rapidly eliminated any residual microbubbles over the course of the first $30 \mathrm{~min}$ of the treatment.

Our data show that $\mathrm{HBO}_{2}$ has a minimal effect on the EGV of individuals without DM, but one that is the opposite of what was predicted. Despite utilizing a GO reaction, the Dexcom G6 CGM does not appear to underestimate glucose values when exposed to high oxygen concentrations. To ensure that glucose is the rate-limiting reactant and that oxygen is present in excess, amperometric CGM sensors based on GO typically surround the working electrode with a glucoselimiting membrane. ${ }^{32}$ The ambient temperature of the sensor wire can also affect EGV, with a 3\%-4\% increase in EGV with each $1{ }^{\circ} \mathrm{C}$ increase in temperature (unpublished data). Ambient temperature in the hyperbaric chamber can fluctuate between $20^{\circ} \mathrm{C}$ and $32.2^{\circ} \mathrm{C}$ with smaller fluctuations on body temperature. We did not collect sensor temperature to determine the effects of the hyperbaric treatment on body

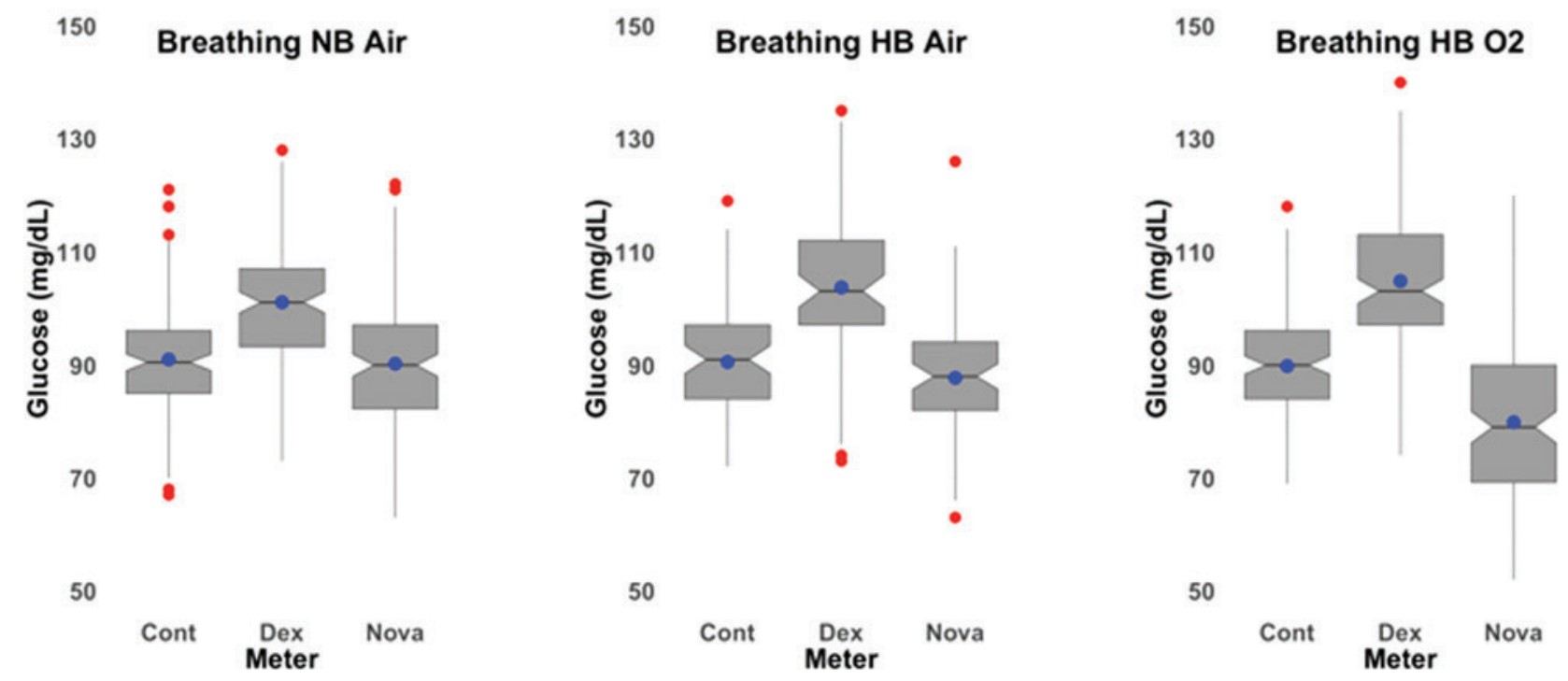

FIG. 4. Box plots of EGV for each glucometer by gas+pressure condition. The Dexcom CGM had a positive bias compared to the two POC glucometers at each gas+pressure condition. The notch displays the $95 \%$ confidence interval around the median value, the blue dot shows the mean value, the box covers the IQR ( 25 th percentile to 75 th percentile), the whiskers add 1.5 times the IQR to the 75 percentile and subtract 1.5 times the IQR from the 25 percentile, and the red dots show outliers. Dex $=$ Dexcom CGM; Nova = Novastat; Cont $=$ Contour. CGM, continuous glucose monitoring; POC, pointof-care. Color images are available online. 
temperature. $\mathrm{HBO}_{2}$ can cause peripheral vasoconstriction, increase systemic vascular resistance and blood pressure, and increase the work of breathing because of the increased density of the inspired gas. ${ }^{33}$ It is unclear why these physiologic changes would affect interstitial temperature or glucose and needs to be further investigated. Future studies will need to record interstitial fluid temperature.

\section{Limitations}

One limitation of our study is that we did not compare any of the CGM or POC readings to a laboratory standard. This is especially relevant given the 2013 Clinical and Laboratory Standards Institute (CLSI) POC testing standards that state:

- At $<100 \mathrm{mg} / \mathrm{dL}, 95 \%$ of results should be within $\pm 12 \mathrm{mg} / \mathrm{dL}$

- At $\geq 100 \mathrm{mg} / \mathrm{dL}, 95 \%$ of results should be within $\pm 12.5 \%$

- At $\leq 75 \mathrm{mg} / \mathrm{dL}, 98 \%$ of results should be within $\pm 15 \mathrm{mg} / \mathrm{dL}$

- At $>75 \mathrm{mg} / \mathrm{dL}, 98 \%$ of results should be within $\pm 20 \%$. $^{24}$

This results in a $25 \%-40 \%$ range of "acceptable" error and potentially makes POC glucometers unreliable as a reference standard. This could explain why we had a positive bias in EGV and higher-than-expected MARD for the CGM. Future studies will need to have EGVs compared to a standardized reference laboratory value.

We did not directly measure blood $\mathrm{pO}_{2}$, but instead used TCOM as a surrogate marker for tissue hyperoxia. TCOM may actually be more representative of the interstitial environment than venous or arterial $\mathrm{pO}_{2}$, but it does not represent arterial or venous $\mathrm{pO}_{2}$. Blood $\mathrm{pO}_{2}$ drops rapidly when exposed to air, but there was a very minimal surface area in the capillary tubes that was exposed to air, and the blood samples were tested within minutes of removal from the hyperbaric chamber. It is unlikely that the $\mathrm{pO}_{2}$ in the blood samples would have dropped significantly between sampling and testing, but this change has not been quantified. Future studies may benefit from blood collection in air-tight syringes to measure blood $\mathrm{pO}_{2}$ to verify hyperoxia.

The EGV generated by the GO reaction used by the CGM sensor should be independent of hyperoxia, but we could not independently verify this to be true. This study did not isolate the GO reaction from a physiologic change in EGV related to $\mathrm{HBO}_{2}$. Therefore, the changes in EGV could either be explained by an intrinsic error in the glucometers caused by hyperoxia, or it could represent a direct physiologic effect of $\mathrm{HBO}_{2}$ on EGV in people without DM. The fact that the two glucometers using a $\mathrm{GO}$ reaction detected changes while the GD reaction glucometer detected no change argues against a direct physiologic effect. In vitro testing of the GO reaction using standardized glucose solutions under hyperbaric conditions is warranted.

We did not perform testing of this device in a monoplace hyperbaric chamber where the patient's entire body is in a $100 \% \mathrm{O}_{2}$ environment because it was not possible to obtain fingerstick $\mathrm{BG}$ samples during $\mathrm{HBO}_{2}$ exposure. However, exposure to $100 \%$ ambient $\mathrm{O}_{2}$ should not affect the readings of the CGM as the sensor wire is completely inserted in the subcutaneous space. Although we did not use the CGM in a monoplace hyperbaric chamber, safety evaluation and testing showed that this CGM should not pose a risk of fire if used in a $100 \% \mathrm{HBO}_{2}$ environment. ${ }^{34}$

We did not test CGMs manufactured by other companies because they had not previously been cleared for hyperbaric use, or they did not have the capacity to transmit data wirelessly through the hull of our multiplace hyperbaric chamber. Because of differences in manufacturing and sampling algorithms, the results from this study should not be extrapolated to other manufacturers' CGMs. Future studies would benefit from comparison to other manufacturers' CGMs.

\section{Conclusions}

In people without DM, there is a statistically significantbut clinically insignificant-effect of gas+pressure condition on the glucose estimate detected by the Dexcom G6 CGM system. Exposure to $\mathrm{HBO}_{2}$ was associated with a statistically significant and potentially clinically relevant decrease in glucose estimate reported by the Novastat glucometer. There is a measurable effect of $\mathrm{HBO}_{2}$ on the EGV of people without DM; however, it is not clinically significant.

\section{Acknowledgments}

We are grateful for the assistance of Bette Manulik, Paul Fitzpatrick, and Kristin Hickey from the Legacy Research Institute for their invaluable assistance in administrative support and data collection during the study.

\section{Author Disclosure Statement}

The following authors (E.H., S.D., C.B., D.S., and J.R.C.) received salary support during the conduct of this study from a research grant provided by Dexcom, Inc. (IIS-2019-002).

J.R.C. has a financial interest in Pacific Diabetes Technologies, Inc., a company that may have a commercial interest in the results of this type of research and technology. This potential conflict of interest has been reviewed and managed by OHSU. In addition, J.R.C. reports advisory board participation for Zealand Pharma and Novo Nordisk and consulting and research support from Dexcom.

\section{Funding Information}

This study was funded by a research grant from Dexcom, Inc.

\section{References}

1. Margolis DJ, Malay DS, Hoffstad OJ: Prevalence of diabetes, diabetic foot ulcer, and lower extremity amputation among Medicare beneficiaries, 2006 to 2008. Diabetic Foot Ulcers. Data Points \#1 (prepared by the University of Pennsylvania DEcIDE Center, under Contract No. HHSA29020050041I). Agency for Healthcare Research and Quality, 2011.

2. Margolis DJ, Malay DS, Hoffstad OJ: Incidence of diabetic foot ulcer and lower extremity amputation among Medicare beneficiaries, 2006 to 2008. Data Points \#2 (prepared by the University of Pennsylvania DEcIDE Center, under Contract No. HHSA29020050041I). Agency for Healthcare Research and Quality, 2011.

3. Huang ET, Mansouri J, Murad MH, et al.: A clinical practice guideline for the use of hyperbaric oxygen therapy 
in the treatment of diabetic foot ulcers. Undersea Hyperb Med 2015;42:205-247.

4. Boyko EJ, Ahroni JH, Cohen V, et al.: Prediction of diabetic foot ulcer occurrence using commonly available clinical information: the Seattle Diabetic Foot Study. Diabetes Care 2006;29:1202-1207.

5. Stevens SL, Narr AJ, Claus PL, et al.: The incidence of hypoglycemia during $\mathrm{HBO}_{2}$ therapy: a retrospective review. Undersea Hyperb Med 2015;42:191-196.

6. Al-Waili NS, Butler GJ, Beale J, et al.: Influences of hyperbaric oxygen on blood pressure, heart rate and blood glucose levels in patients with diabetes mellitus and hypertension. Arch Med Res 2006;37:991-997.

7. Trytko B: Does hyperbaric oxygen affect blood sugar levels in diabetics? (Abstract only). SPUMS J 2002;32:1.

8. Heyboer M, Wojcik SM, Swaby J, Boes T: Blood glucose levels in diabetic patients undergoing hyperbaric oxygen therapy. Undersea Hyperb Med 2019;46:437-445.

9. Niezgoda JA, Kingston W, Fabus S: Effects of hyperbaric oygen on blood glucose levels [Abstract]. Undersea and Hyperbaric Medicine 2002.

10. Fife C, Warriner RA, Pasceri R, et al.: The effect of hyperbaric treatment pressure and air breaks on blood glucose levels: results of an ongoing study [Abstract]. Undersea Hyperb Med 2007;34:245.

11. Perdrizet G, Gasho K, Fan L, Qureshi I: Does hyperbaric oxygen therapy cause hypoglycemia in diabetic patients? A review of 119 diabetic patients treated in a multiplace chamber [Abstract]. Undersea Hyperb Med 2007;34:246247.

12. Capelli-Schellpfeffer M, Philipson L, Bier M, et al.: HBO and hypoglycemia in diabetic surgical patients with chronic wounds (Abstract). Undersea Hyperb Med 1996;23(Supplement):81.

13. Springer R: The importance of glucometer testing of diabetic patients pre and post dive. Undersea Biomed Res 1991;18(Supplement):20.

14. Rose R, Rice J, Kraft K, et al.: An ongoing study of plasma glucose measurement in diabetic patients during hyperbaric oxygen therapy (HBO) [ABSTRACT]. Undersea Hyperb Med 2001;28(Supplement):32.

15. Wilkinson D, Nolting M, Mahadi MK, et al.: Hyperbaric oxygen therapy increases insulin sensitivity in overweight men with and without type 2 diabetes. Diving Hyperb Med 2015;45:30-36.

16. Stevens SL, Sorita A, Narr AJ, et al.: Applying quality improvement methods in a hyperbaric oxygen program: reducing unnecessary glucose testing. Undersea Hyperb Med 2016;43:427-435.

17. Juvenile Diabetes Research Foundation Continuous Glucose Monitoring Study G: Effectiveness of continuous glucose monitoring in a clinical care environment: evidence from the Juvenile Diabetes Research Foundation continuous glucose monitoring (JDRF-CGM) trial. Diabetes Care 2010;33:17-22.

18. Davey RJ, Jones TW, Fournier PA: Effect of short-term use of a continuous glucose monitoring system with a real-time glucose display and a low glucose alarm on incidence and duration of hypoglycemia in a home setting in type 1 diabetes mellitus. J Diabetes Sci Technol 2010;4: 1457-1464.
19. Adolfsson P, Ornhagen H, Eriksson BM, et al.: Continuous glucose monitoring - a study of the Enlite sensor during hypo- and hyperbaric conditions. Diabetes Technol Ther 2012;14:527-532.

20. Adolfsson P, Ornhagen H, Eriksson BM, et al.: In-vitro performance of the Enlite Sensor in various glucose concentrations during hypobaric and hyperbaric conditions. J Diabetes Sci Technol 2012;6:1375-1382.

21. Vote DA, Doar O, Moon RE, Toffaletti JG: Blood glucose meter performance under hyperbaric oxygen conditions. Clin Chim Acta 2001;305:81-87.

22. Price ME, Jr., Hammett-Stabler C, Kemper GB, et al.: Evaluation of glucose monitoring devices in the hyperbaric chamber. Mil Med 1995;160:143-146.

23. Tang Z, Louie RF, Lee JH, et al.: Oxygen effects on glucose meter measurements with glucose dehydrogenase- and oxidase-based test strips for point-of-care testing. Crit Care Med 2001;29:1062-1070.

24. Rajendran R, Rayman G: Point-of-care blood glucose testing for diabetes care in hospitalized patients: an evidencebased review. J Diabetes Sci Technol 2014;8:1081-1090.

25. Liu Y: Box plots: use and interpretation. Transfusion 2008; 48:2279-2280.

26. Doyle D: Notched Box Plots. https://sites.google.com/site/ davidsstatistics/home/notched-box-plots (accessed January 22, 2020).

27. Ekanayake L, Doolette D: Effects of hyperbaric oxygen treatment on blood sugar levels and insulin levels in diabetics. SPUMS J 2001;31:16-20.

28. Villena Gonzales W, Mobashsher AT, Abbosh A: The progress of glucose monitoring-a review of invasive to minimally and non-invasive techniques, devices and sensors. Sensors (Basel) 2019;19:E800.

29. Vote DA, Doar O, Moon RE, Toffaletti JG: Measurement of plasma glucose under hyperbaric oxygen conditions. SPUMS J 2000;30:182-186.

30. Wilkinson D, Chapman IM, Heilbronn LK: Hyperbaric oxygen therapy improves peripheral insulin sensitivity in humans. Diabet Med 2012;29:986-989.

31. Dexcom G6 Mobile Continuous Glucose Monitoring System User Guide: In. Vol LBL014003 Rev 010 MT23976. San Diego, CA: Dexcom, Inc., 2018.

32. Hoss U, Budiman ES: Factory-calibrated continuous glucose sensors: the science behind the technology. Diabetes Technol Ther 2017;19(S2):S44-S50.

33. Weaver LK, Howe S, Snow GL, Deru K: Arterial and pulmonary arterial hemodynamics and oxygen delivery/ extraction in normal humans exposed to hyperbaric air and oxygen. J Appl Physiol (1985) 2009;107:336-345.

34. Bliss C, Huang E, Savaser D: Safety of a continuous glucose monitoring device during hyperbaric exposure. Undersea Hyperb Med 2020;47:13-19.

Address correspondence to: Enoch Huang, MD

Legacy Emanuel Medical Center 3001 N. Gantenbein Avenue Portland, OR 97227

E-mail: enoch.huang@mac.com 